15

\title{
Создание дифракционной решетки на алмазной подложке имплантацией ионами бора
}

\author{
() А.Л. Степанов ${ }^{1,2,3}$, В.И. Нуждин ${ }^{1}$, М.Ф. Галяутдинов ${ }^{1}$, \\ Н.В. Курбатова ${ }^{1}$, В.Ф. Валеев ${ }^{1}$, В.В. Воробьев ${ }^{2}$, Ю.Н. Осин ${ }^{2}$ \\ ${ }^{1}$ Казанский физико-технический институт им. Е.К. Завойского \\ Казанского научного центра РАН \\ ${ }^{2}$ Казанский федеральный университет \\ ${ }^{3}$ Казанский национальный исследовательский технологический \\ университет \\ E-mail: aanstep@gmail.com
}

Поступило в Редакцию 23 июня 2016 г.

Настоящее исследование относится к способам изготовления дифракционных оптических элементов (дифракционных решеток). Дифракционная решетка была получена на основе алмаза при его имплантации ионами бора через маску. В процессе имплантации в немаскированных областях облучаемого алмаза произошла графитизация алмаза, приведшая к распуханию облученного слоя. Формирование периодических поверхностных графитизированных микроструктур на поверхности алмаза контролировалось методами оптической, электронной и атомно-силовой микроскопии. Эффективность функционирования дифракционного оптического алмазного элемента показана путем его зондирования излучением гелий-неонового лазера.

DOI: 10.21883/PJTF.2017.02.44185.16385

Задачи современной интегральной оптики требуют использования новых специальных материалов, а также разработки технологий изготовления рабочих компонентов и устройств на их основе. Одно из характерных направлений заключается в развитии алмазной оптики [1]. Использование алмаза обусловлено его радиационной (лучевой) стойкостью и высокой теплопроводностью. Алмазные оптические элементы, обладая широким окном прозрачности от 0.2 до $5 \mu \mathrm{m}$, могут работать при резких перепадах температуры и в агрессивных химических средах. На практике алмазы используются для изготовления различных 
дифракционных оптических элементов (ДОЭ): решеток, киноформов, фокусаторов, корректоров и др. [1,2]. Алмазные ДОЭ могут применяться для преобразования пучков высокомощного $\mathrm{CO}_{2}$-лазера, на котором удается получать плотности мощности освещающего пучка до $20 \mathrm{~kW} / \mathrm{cm}^{2}$ [3,4]; для создания фотонно-кристаллических резонаторов с целью реализации квантовых механизмов хранения информации [5]; для управления потоками излучения в рентгеновской оптике, например, при использовании алмазных брэгговских зеркал с коэффициентом отражения $\sim 100 \%$ [6] и т.д.

Для получения периодических ДОЭ на поверхности алмаза используются различные технологические способы, такие как воздействие мощными импульсами эксимерного лазера [7], травление в газовом потоке транспортного газа [8] и др. В настоящей работе представлен новый подход, который заключается в формировании на поверхности полированного алмаза периодических дифракционных структур методом ионной имплантации через поверхностную маску. Ранее данная технология была успешно использована для получения ДОЭ на диэлектрических и полимерных подложках при их имплантации ионами благородных металлов [9-11]. Таким образом, конкретная задача заключается в исследовании возможности получения ДОЭ на алмазе методом имплантации ионами бора через поверхностную маску.

Для формирования ДОЭ на полированной поверхности искусственного алмаза проводилась имплантация ионами бора с энергией $E=$ $=40 \mathrm{keV}$, дозой облучения $D=1.3 \cdot 10^{18} \mathrm{ion} / \mathrm{cm}^{2}$ при плотности тока в ионном пучке $J=15 \mu \mathrm{A} / \mathrm{cm}^{2}$ на ионном ускорителе ИЛУ-3 через поверхностную маску - никелевую сетку с размером квадратных ячеек $40 \mu \mathrm{m}$. Локальная морфология и структура поверхности имплантированного алмаза были исследованы методами сканирующей электронной микроскопии (СЭМ) на СЭМ-микроскопе Merlin (Carl Zeiss), оснащенном детектором дифракции отраженных электронов HKL NordLys (Oxford Instruments), а также атомно-силовой микроскопии (ACM) в полуконтактной моде с помощью АСМ-микроскопа FastScan (Brucker). Оптическая характеризация ДОЭ проводилась с помощью оптического микроскопа Полар-1 (Микромед) и при измерении рамановского спектра по методике, описанной в работе [12]. Анализ оптических дифракционных картин от ДОЭ осуществлялся при их зондировании гелий-неоновым лазером на длине волны $632.8 \mathrm{~nm}$. Моделирование концентрационных профилей распределения имплантированного бора с

Письма в ЖТФ, 2017, том 43, вып. 2 


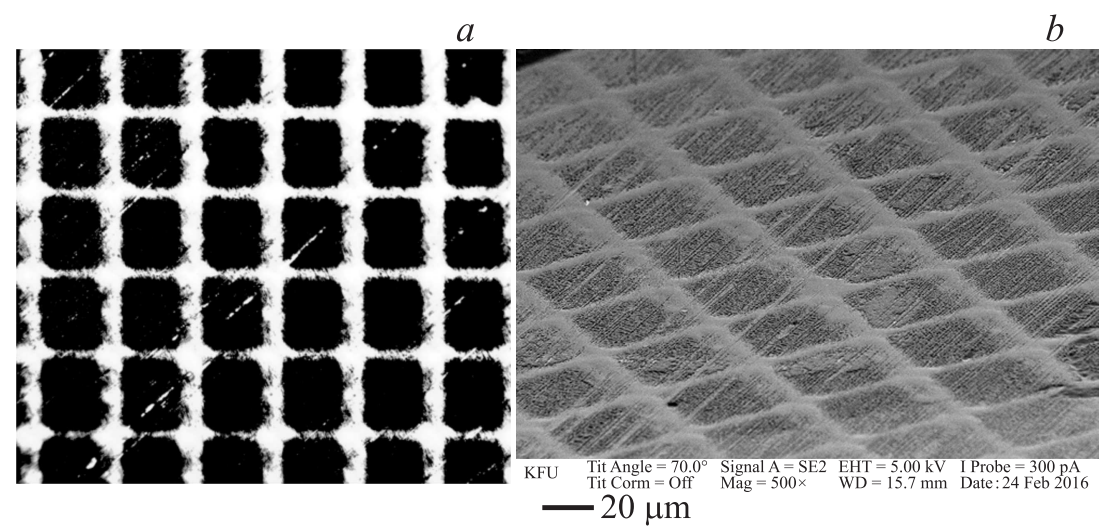

Рис. 1. Изображения имплантированного через маску ионами бора алмаза, наблюдаемые на оптическом $(a)$ и электронном $(b)$ микроскопах.

энергией $40 \mathrm{keV}$ в алмазе по глубине с помощью алгоритма SRIM-2013 показало, что атомы бора накапливаются в приповерхностном слое алмаза толщиной $\sim 100 \mathrm{~nm}$.

На рис. 1 приведены изображения решетки, сформированной на поверхности алмаза имплантацией ионами бора через поверхностную маску, наблюдаемые на оптическом $(a)$ и под углом $70^{\circ}$ на СЭМ $(b)$ микроскопах. Как видно из приведенных изображений, периодическая микроструктура состоит из чередующихся темных квадратных ячеек, относящихся к имплантированным участкам поверхности образца, разделенных стенками (светлые области) неимплантированного алмаза. Размер имплантированных участков соответствует размеру ячеек используемой маски $40 \mu \mathrm{m}$.

Структурная характеризация исходного и имплантированных участков алмаза проводилась методом дифракции отраженных электронов при зондировании приповерхностной области образца. В отличие от дифракции Кикучи в виде полос, параллельных плоскостям кристаллической решетки алмаза, для областей, облученных ионами бора, в картине дифракции наблюдаются только широкие диффузные кольца, указывающие на разрушение кристаллической решетки в приповерхностном слое имплантированного алмаза и формирование аморфных углеродных образований. 


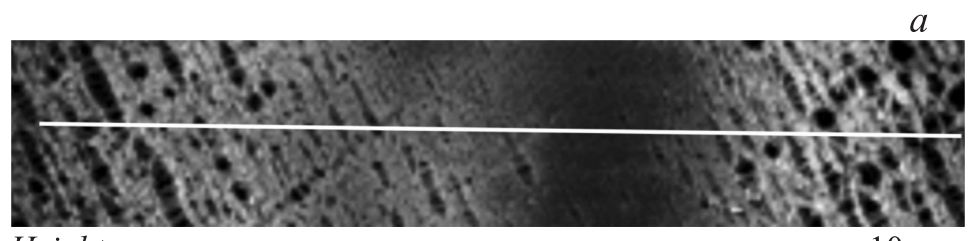

Height sensor

$10 \mu \mathrm{m}$

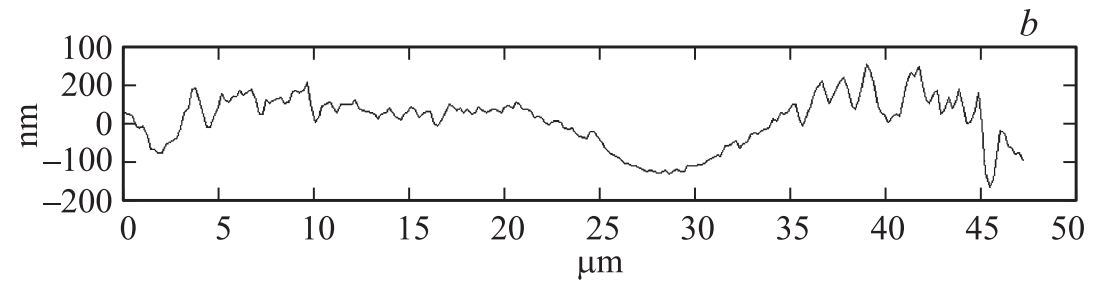

Рис. 2. $a-$ АСМ-изображение поверхности фрагмента алмазной дифракционной решетки в областях необлученной перегородки алмаза (темная часть рисунка) и имплантированных ячеек (светлые части рисунка); светлой линией указано направление измерения поперечного сечения. $b$ - профиль поперечного сечения, измеренный по направлению, указанному на $a$.

На рис. 2, $а$ приведено АСМ-изображение фрагмента алмазного ДОЭ вблизи стенки (темная область) между имплантированными ячейками (светлые шероховатые области). На рис. 2, $b$, показан профиль поперечного сечения, измеренный по направлению, указанному на рис. 2, $a$. Из рисунка следует, что имплантированные ионами бора участки поверхности алмаза (ячейки) возвышаются над поверхностью алмаза на $\sim 100 \mathrm{~nm}$. Такой эффект объясняется распуханием облученных участков (ячеек решетки) образца, характеризуемых меньшей плотностью $\left(\rho_{\text {graphite }}=2.09-2.23 \mathrm{~g} / \mathrm{cm}^{3}\right)$ по сравнению с алмазом (неграфитизированным материалом; $\rho_{\text {diamond }}=3.47-3.55 \mathrm{~g} / \mathrm{cm}^{3}$ ) [13]. Измерение рамановских спектров при возбуждении аргоновым лазером на длине волны $522 \mathrm{~nm}$ также подтверждает разрушение алмаза, поскольку в спектре, наряду с хорошо известной для алмаза интенсивной линией $1336 \mathrm{~cm}^{-1}$ [14], после имплантации появляются более слабые линии в области $1560 \mathrm{~cm}^{-1}$, указывающие на его графитизацию [13]. В результате имплантации алмаза ионами бора и разрушения его решетки следовало бы ожидать образования карбида бора при связывании атомов

Письма в ЖТФ, 2017, том 43, вып. 2 


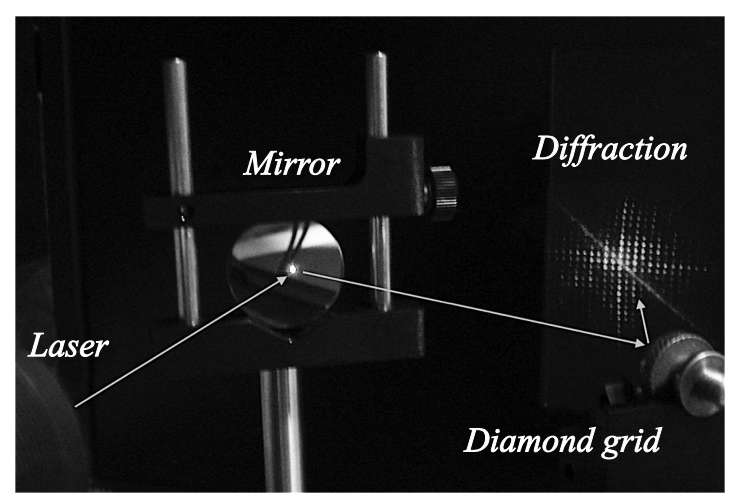

Рис. 3. Изображение картины дифракционного рассеяния на экране, полученное на отражение от алмазной решетки при зондировании гелий-неоновым лазером. Образец с алмазной решеткой закреплен на металлическом держателе.

углерода и бора. Однако соответствующих кристаллитам карбида бора характерных линий в рамановском спектре в определенной области от 200 и до $1200 \mathrm{~cm}^{-1}$ [15] обнаружено не было. Тем не менее, как следует из работы [16], отдельные химические связи или малые фрагменты, состоящие из атомов бора и углерода, напрямую не распознаваемые рамановской спектроскопией, могут присутствовать в графитизированных областях имплантированного ионами бора алмаза.

Имплантация алмаза ионами бора ведет как к изменению химического состава (накопление бора в образце), так и к модификации его фазовой углеродной структуры, т.е. образованию периодических областей графитизированного материала. В результате имплантации алмаза через поверхностную маску формируется микроструктура с периодически изменяемым распределением оптических констант материала, т. е. между стенками решетки из алмаза (с показателем преломления $\left.n_{\text {diamond }}=2.42\right)$ и графитизированными ячейками $\left(n_{\text {graphite }}=2.1-2.23\right)$. Поэтому сформированная периодическая микроструктура с графитизированными областями на алмазе может быть использована на практике в качестве двумерного фотонного кристалла или ДОЭ. В качестве иллюстрации на рис. 3 приведено дифракционное изображение, регистрируемое при зондировании алмазной решетки гелий-неоновым

Письма в ЖТФ, 2017, том 43, вып. 2 
лазером на длине волны $632.8 \mathrm{~nm}$ света на отражение. Очевидно, что, манипулируя режимами ионной имплантации, меняя тем самым эффективный показатель преломления отдельных областей в ДОЭ, можно управлять его оптическими и дифракционными характеристиками.

Таким образом, в настоящей работе рассмотрен процесс низкоэнергетической высокодозовой имплантации алмаза ионами бора через поверхностную маску и продемонстрирована методика создания ДОЭ на его основе при низкоэнергетической высокодозовой ионной имплантации через поверхностную маску. В результате на поверхности алмаза получена дифракционная микроструктура, фазовый контраст в которой обеспечивается графитизированными областями алмаза. Основным практическим применением полученных результатов является развитие направления и создание новых эффективных элементов алмазной оптики.

Данная работа была поддержана грантом РФФИ № 15-48-02525.

\section{Список литературы}

[1] Раткин Л. // Фотоника. 2011. № 4. С. 18-23.

[2] Сойбер В.A. Методы компьютерной оптики. М.: Физматлит, 2003.

[3] Коненко В.В., Конов В.И., Пименов С.М. и др. // Квантовая электроника. 1999. T. 26. № 1. С. $9-10$.

[4] Karlsson M., Nikolajeff F. // Opt. Express. 2003. V. 11. P. 502-507.

[5] Тукмаков К.Н., Володин Б.О., Павельев В.С. и др. // Вестник Самарского аэрокосмического госуниверситета. 2012. Т. 7. В. 38. С. 112-116.

[6] Shvydko Y., Stopin S., Blank V., Terentev S. // Nat. Photon. 2011. V. 5. P. 539-542.

[7] Веревкин Ю.К., Бронникова Н.Г., Королихин В.В. и др. // ЖТФ. 2003. Т. 73. C. $99-102$.

[8] Волков А.В., Казанский Н.Л., Моисеев О.Ю., Сойбер В.А. Способ изготовления дифракционных оптических элементов на алмазных и алмазоподобных подложках: Патент РФ № 2197006. 2003.

[9] Stepanov A.L., Galyautdinov M.F., Evlyukhin A.B. et al. // Appl. Phys. A. 2013. V. 111. P. 261-264.

[10] Степанов А.Л., Нуждин В.И., Валеев В.Ф., Галяутдинов М.Ф., Осин Ю.Н. Дифракционная решетка: Патент РФ № 140494. 2014.

[11] Галяутдинов М.Ф., Нуждин В.И., Фаттахов Я.В. и др. // Письма в ЖТФ. 2016. T. 42. B. 4. C. 30-37.

Письма в ЖТФ, 2017, том 43, вып. 2 
[12] Курбатова Н.В., Галяутдинов М.Ф., Иванов Н.А и др. // ФТТ. 2013. Т. 55. B. 9. C. $1784-1787$.

[13] Хмельницкий Р.А. Радиационное повреждение и графитизация алмаза при ионной имплантации: Дис. ... канд. физ.-мат. наук. М., 2008. 97 с.

[14] Deslandes A., Guenette M.C., Belay K. et al. // Nucl. Instr. Metn. Phys. Res. B. 2015. V. 365. P. 331-335.

[15] Hushur A., Manghnani M., Werheit H. et al. // J. Phys.: Condens. Matter. 2016. V. 28. P. 045403 (1-5).

[16] Domnich V., Reynaud S., Haber R.A., Chhowalla M. // J. Am. Ceram. Soc. 2011. V. 94. P. $3605-3628$. 